\title{
Negotiating/Constructing Identity in Deena Mohamed's Webcomic "Qahera”
}

\author{
Samar Abdelsalam*
}

\section{Introduction}

Forms of expression have changed significantly over the past decades. With the development of mass media and the rapid transmission of information, there appeared a shift from word-based texts to other forms of expression; such as graphic novels, vlogs and memes, the study of which as an academic discipline has started to gain momentum since the 1970s. Webcomics, or online series of comic strips, have also emerged over the past years as a powerful tool that allows for a parallel narrative which enjoys freedom of expression in both form and content. Well written ones enjoy a dramatic sense and convey a powerful message that bears within its confines an entire set of dramatic elements.

Studies on comics have ranged from the simplistic reading of a different form of expression aiming at the entertainment of young adults in the 1950s, to the sophisticated interpretation of the relationships between comics as an art form on the one hand, and the challenges they pose to the conventions of identity formation imposed upon (or embraced by) individuals through state, culture, gender, or religious institutions throughout the last decades, on the other hand (Cortsen, La Cour \& Magnussen 2015, p. xvii). Though comics studies have witnessed an extensive surge, and research has expanded widely in the Northern hemisphere, ${ }^{1}$ it remains a very understudied genre in the Middle East. Therefore, the present paper examines Deena Mohamed's Qahera, an Egyptian webcomic that has received positive reviews but no in-depth analysis, by employing Homi Bahba's Third Space theory, and a feminist approach to identity formation.

Among the artists who have appeared on the Arab comics arena lately is Deena Mohamed, a young artist, blogger and illustrator. In 2013, she created "Qahera", a seemingly fleeting internet trend that soon transformed into a wellestablished webcomic. ${ }^{2}$ The focus of this paper is the webcomic Qahera, with its eight parts published between 2013 and 2015, featuring Qahera, a female superhero. Apart from Part Five, which functions as a comic interlude, ${ }^{3}$ the remaining seven are grouped under two sections. Parts One, Two and Seven are studied within the discussion of the secular and Islamic dichotomy, while Parts

\footnotetext{
* Faculty of Al-Alsun (Languages), Ain Shams University, Egypt. Cairo Studies in English (2018): https://cse.journals.ekb.eg/
} 
Three, Four, Six, and Eight are grouped under the dichotomy of the individual versus the collective.

\section{Theoretical Framework and Context}

The present paper depends on Third Space theory, on different levels, in its analysis of both Qahera, the character, and Qahera, the webcomic. Homi Bhabha's notion of Third Space is used to explain how the Superhero Qahera (as a representative of the Arab, Egyptian, Muslim, veiled female) manages to develop a unique, gendered subjectivity, and create a third space, where she would negotiate and construct an identity that is strong enough to combat Islamophobia, harassment, and patriarchy. The choice of Third Space, in particular, stems from the fact that "[t]hird refers to the constructing and reconstructing of identity, to the fluidity of space. In cultural studies literature, third is used to denote the place where negotiation takes place, where identity is constructed and reconstructed, where life in all its ambiguity is played out" (English 2005, 87). Yet, the paper does not confine its viewpoint to the cultural interpretation alone, but also embraces the extended interpretation of Bhabha's theory to include some aspects of what Karin Ikas and Gerhard Wagner describe as the reconstruction of "its logical, philosophical, psychological, sociological, geographical and ... political meaning" $(2009,2)$.

On the level of the webcomic, the paper also extends Homi Bhabha's Third Space into its broader sense adopted by media art theories, which maintain that "third space represents the fusion of the physical (first space) and the remote (second space) into a third space that can be inhabited by remote users simultaneously or asynchronously" (Packer 2014). Deena Mohamed (the physical writer, first space) and the target audience (remote space), meet virtually at Qahera which, thus, constitutes third space, especially "[b]ecause Mohamed not only expands the boundaries of what Islamic feminism can look like, as well as answers questions from individuals wanting to learn more about her culture, she works to disrupt assumptions about Islamic culture gained through media consumption" (Ivey 2015, 384). Qahera functions as a shocking personality that subverts stereotypes about Muslim women both in Egypt and abroad.

Dittmer and Latham describe this in terms of multiplicity that comprises both the actual and the virtual, explaining that "wherever a reader might be in a comic the panels she or he have seen previously are virtually present in her or his mind, but pushing this further, other possible contingent readings of the comic are also virtualities. This multiplicity is complemented by another, the doubling of 'our' world and that produced within the comic" $(2015,440)$. Such an opinion credits the notion of the third space that is created through the combination of the 
reader's world and the comic's world. Qahera creates such a third space particularly for women - by providing a fresh venue that is neither their own, nor the imaginary one of the webcomic. D. Wolk explains it further:

The broader philosophical implication of many comics, to one extent or another, is: there is another world, which is this world. The places that cartoonists draw are very different from the ones where readers live; every element of the comics world is created by the artist's hands. The cartoonist's image-world is a metaphorical representation of our own, though, and it can be mapped onto ours. (qtd in Dittmer and Latham 2015, 440)

Whether similar to the reader's world or different from it, the reader's interaction with the webcomic's world can provide a Third Space that gives the reader insight into his/her surroundings.

The paper also tackles the problems raised by the fact that the webcomic was originally written in English and directed to Western recipients, then later translated into colloquial Arabic starting from the third part. As Mohamed puts it, "the shift in language and process of translation radically transformed the content of the comic, adapting it to different constituencies and a rapidly diversifying set of audiences" (Mohamed 2017, 138). ${ }^{4}$ Mohamed admits that her choice to write the comic originally in English influenced key aspects of both Qahera, the webcomic, and Qahera, the character, from the very beginning, in addition to affecting "visible aspects of her identity, the most obvious of which is the hijab, which is viewed far more negatively in the West where visibly Muslim women tend to bear the brunt of Islamophobia" (Mohamed 2016, 140). Mohamed argues that such visual aspects would not have mattered much had the comic been originally directed to Arab audiences $(2016,140)$, but it remains questionable whether she would have created a totally different physiognomy. Mohamed's words seem to suggest that the choice of appearance was meant to shock the Western audience with a visibly Muslim superhero: ${ }^{5}$ "By deliberately moving away from the superhero aesthetic, the website differentiates itself and attempts to appeal to a different audience" (Jones 2017, 1085). Admittedly, Qahera's success constitutes a curious phenomenon, given its relatability to many feminist sentiments, yet its estrangement from common forms of expression and limited demographic appeal at the same time.

Walking the very fine line of harshly critiquing society without compromising her Muslim and Arab heritage, Deena Mohamed creates a female superhero that powerfully stands against misogyny, combats Islamophobia and confronts street 
harassment, against a backdrop of Egyptian protests. She plays an active role both as the creator of the work and as the leading character, because " $[\mathrm{t}] \mathrm{hrough}$ her artistic and political interventions in this online medium, Mohamed 'combats' the epistemic violence committed against her culture, one frame (and question) at a time" (Ivey 2015, 387). Both Mohamed and Qahera engage in cultural and social dialogues, one through answering questions about her webcomic and the other through actively trying to effect change.

Deena Mohamed's superhero, Qahera (which means vanquisher, conqueror, triumphant, and is also the Arabic equivalent of Cairo), appears as a deviation from the common female roles/stereotypes that range from the docile wife and mother who succumbs to male superiority, to the seductress femme fatale who uses her feminine wiles to achieve her goals. Deena Mohamed's Qahera is an Egyptian, Muslim Superhero who is mirrored against a taboo-oriented society, and inevitably walks through land-mines, brought closer to the surface by the revolution-raised controversies. Mohamed could be said to represent Islamic feminism while opposing radical forms of feminism that disdain religion. This particular point is important, because "[s]eparatism is not an option for Islamic feminists who believe in the possibility of creating the conditions in which multiple identities, including the religious, can coexist in safety and with dignity" (Cooke 2000, 92). Mohamed insists on the possibility of negotiating and constructing an identity that embraces religious rituals and works toward establishing a society where she can function as an equally appreciated individual. She introduces what could be described as "a gendered text for a gendered audience" (Jones 2017, 1074). Qahera functions as both a female's cry for recognition and an attempt at reaching women within - and without - her own society.

Peter Coogan differentiates between a superhero, and other non-superheroes, on the basis of the former possessing a mission, powers and identity, the last of which would not be complete without "the codename and the costume" (2009, 86) as a superhero's costume is meant to "emblematize the character's identity" $(2009,79)$. Such a description fits Qahera aptly; she is a superhero on a mission of saving women; she is powerful and can fly, and her costume is certainly catching! Qahera blurs the distinction between the superhero's costume and the Muslim woman's everyday attire, thus implying that all women could be superheroes. Some - including Qahera - would argue that all Egyptian women are, in fact, superheroes for putting up with what they face on a daily basis.

As a character, a superhero with an identity of her own, Qahera differs from many Western superheroes who are "spun off" from male superhero franchise. Thus, their code names (e.g., Batgirl, Supergirl) inevitably render their own inner character and biography as secondary to the originating male superhero's 
identity" (Scott 2015, 155). The name "Qahera" stands out as a unique reflection of the Egyptian superhero's identity. Qahera's difference from the Western female superheroes continues with the costume too:

Their costumes function similarly, subsuming the superheroine's identity by using variants on the male superhero's immediately recognizable emblem (Superman's chevron S, Batman's bat silhouette, and so on). It is simple enough to argue that what is really being externalized and emblematized is the logic of franchising. However, when these superheroine identities are always already embedded in another man's origin story, it is difficult not to read the choices surrounding superheroine costuming as, first and foremost, emblematizing the comic-book industry's ongoing commitment to a male, cisgender, heteronormative readership, and the presumption that this demographic desires (or demands) sexual objectification. (Scott 2015, 155)

Qahera's visibly Islamic outfit (Figure 1) provides her with an edge that is unavailable to the female, Western superheroes in the sense that it saves her the objectification - sexual or otherwise - based on the fact that she is somebody's sidekick. Her autonomous presence allows her a distinct, gendered subjectivity that is recognizable irrespective of other entities. In this sense, Qahera is different from women wearing hijab under pressure from society or male authority, thus succumbing to an act of oppression. Her choice provides her with the autonomy that results from an act of agency.

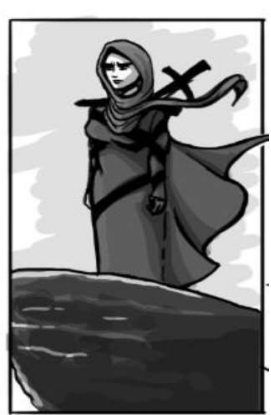

Figure 1:

Qahera 2013, Part $1 .^{6}$

While the sizes, shapes, and dimensions of the panels vary, thus creating varying effects, the webcomic is consistently and fittingly drawn in black and white, with focus on shade to clarify or mystify a given situation. Total dependence on black and white highlights the multiple dichotomies Qahera tackles. The most prominent of those could be the divide between Qahera's values and her community or the dichotomy between the extremism of thirdwave feminism and the extremism of oppressively conservative Eastern communities. Mohamed emerges as one of those women who "are constructing new identities and negotiating a new presence in places where before they had been invisible" (Cooke 2000, 91). Her decision to draw the panels without colour directly reflects Qahera's perspective of her mission as she seems to view all conflicts in black and white and shows neither hesitation nor ambiguousness when it comes to the individuals or ideologies she opposes. Moreover, with the 
black-white combination grey inevitably emerges, thus symbolically creating the Third Space of in-betweenness and ambivalence - a greyish zone where many women reside.

\section{Negotiating/Constructing Identity within the Secular/Islamic Dichotomy}

Three of Mohamed's eight-part webcomic tackle Muslim women's attempts at negotiating and reconstructing their identities within the secular/Islamic dichotomy. Parts One, Two and Seven discuss the long established, mostly colonial, division between the secular and the Islamic, exhibiting women's dilemma of having to belong to one camp and being dismissed by the other, as either an advanced atheist or a primitive believer. One of the main issues raised within this dichotomy is whether women's movement could be immersed in the local, with its economic, social, political and cultural aspects, and still be inspired by justice and able to confront oppressions of all types (El Said, Meari, and Pratt 2015, 23). The solution is provided by Mohamed who adopts a third space whereby she rejects the polarity and binary opposition inherent in the available options, in favour of a gendered subjectivity that allows her freedom of choice, on her own terms.

The first webcomic was posted on June 30, 2013. It starts with a wide horizontal panel, featuring the upper half of Qahera's face, with a focus on her frown and her determined eyes. Mohamed moves to two vertical panels: The first features Qahera in full view, revealing her hijab, ground-long attire, and her sword visibly hanging behind her back, while the second panel positions her in a Spiderman squat, with one hand on the ground, complaining that she "can hear it! The sound of ... misogynistic trash!" (Qahera 2013, Part 1). Another wide, horizontal panel features a Muslim Sheikh addressing a group of wide-eyed, brain-washed followers who listen attentively to his sermon: "A good wife is an attentive wife! It is your Islamic duty to keep your wives at home and in check!" (Qahera 2013, Part 1). Qahera's response is an attack on the misogynist whom she punishes by dangling him from a laundry rope by clips from the shoulder and leaving him there to dry! The same intolerance is shown to western feminists who attempt to "rescue" Muslim women.

Mohamed manages to subtly show the similarities between both types of extremism through the comic. The panel featuring the Sheikh and his followers is drawn in the same shape, proportion, and frame as the one introducing the Western feminist fanatic and her followers (Figures $2 \& 3$ ). Both are wide, horizontal panels where the authoritative figure is standing in control, addressing a group of eagerly attentive, blindly submissive figures, looking up to their idol. Both panels make sure to diversify the recipients: the Muslim fanatics include long-bearded, clean-shaven, and heavy stubble bearers, showing that differences 
in the degree of Islamic commitment do not prevent them all from adhering to the one rule of keeping their women under their protective wing. The same applies to the feminist fanatics who are mostly females of all shapes (long straight hair, short hair, long curly hair), in addition to one male, all focused on the sleeveless leader advocating the rescue mission. The only difference is the presence of the male in the Western scene against the absence of females in the Islamic one. Mohamed portrays an Islamic world where women are invisible, versus a Western scene that - despite extremism - has room for both genders. Such a similarity is enforced through what Dittmer and Latham describe as "iconic solidarity" that links "two panels and implies that they form part of a narrative, but it is the difference between the panels that is productive" (2015, 436). The formal similarity between the two panels versus the different content serves to crystalize the extremism that each advocates.

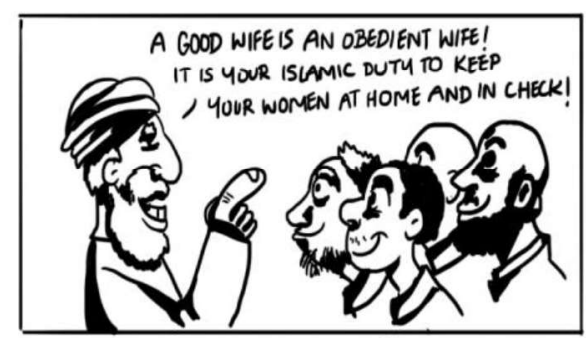

Figure 2, Qahera 2013, Part 1.

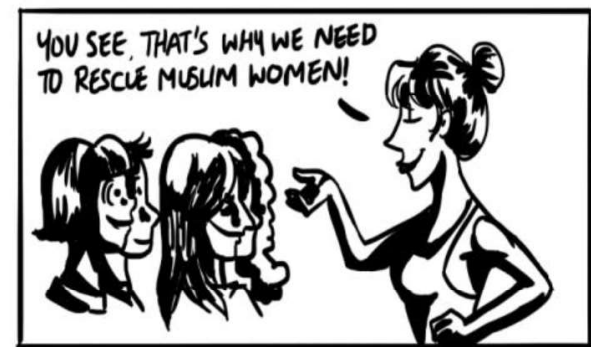

Figure 3, Qahera 2013, Part 1.

Part One establishes the superhero's inability to tolerate both Islamist/Arab "misogynistic trash" and Western "white feminists who try to co-opt the struggle" (Qahera 2013, Part 1). Qahera's decision to fight both sets the tone of the entire comic from the very beginning. This is a superhero with both roots and wings. Mohamed explains, in an article on Qahera, that the webcomic constituted a real challenge for her as she was "careful to signal a warning to Western, liberal feminists who [she] knew would inevitably hijack Qahera to serve their own purposes," and relates that she was constantly "frustrated at being unable to critique [her] own community without having [her] own narrative used against [her]" (Mohamed 2016, 140). By rejecting the two extremes, "Mohamed reconstructs difference as a performance of Homi Bhabha's Third Space. Instead of becoming an objectified spectacle that affirms normative bodies, Qahera's visibility [...] disrupts binary oppositions naturalised by the hegemonic discourses of Arab patriarchy and Western feminism regarding what constitutes a 'normal' body" (Barkuzar 2017, 433). Qahera re-defines normality by resisting the objectification that such a binary opposition enforces. Her acceptance of her physiognomy and embracing of her 
heritage help her negotiate with different forms of extremism and construct her unique identity.

Part Two of the webcomic appeared on 20 July 2013. It resumes the attack on extremist Western feminism by featuring FEMEN, a radical Ukrainian feminist group that is famous for its highly controversial, topless protests against sex trade, patriarchy, dictatorship, and religious entities. FEMEN's official online page declares that their mission is to "protest" and their weapon is "bare breasts" in order to achieve the goal of "complete victory over patriarchy," through an ideology of "Sextremism, Atheism, [and] Feminism," which requires the "immediate political deposition of all dictatorial regimes creating unbearable living conditions for women, first of all, theocratic Islamic states practicing Shari' ah and other forms of sadism regarding women" (FEMEN 2018). FEMEN is not only clearly at odds with all Islamic factions (regardless of how liberal some of them might be), but also with what Qahera herself stands for. FEMEN's obsession with nudity "feeds into and reinforces a racist and orientalist discourse about the women and men of north Africa and the Middle East. ... Femen [sic] positions women of the region as veiled and oppressed by their men as opposed to the enlightened and liberated women of the west who live in a developed and superior society where they have the 'freedom' to remove their clothes" (Nagarajan 2013). FEMEN's patronizing attitude towards Muslim women stems from a colonizing heritage that only sees the different "Other" as inferior.

It is significant that Mohamed chooses the third wave of feminism, or Feminazis, as the other end of the spectrum from Islamic fanaticism. Her decision to reject both, with equal enthusiasm, helps her solidify her own gendered subjectivity and create a Third Space of her own, where she does not belong to either camp. Qahera advocates a third space where

The aim of cultural difference is to rearticulate the sum of knowledge from the perspective of the signifying position of the minority that resists totalization - the repetition that will not return as the same, the minus-inorigin that results in political and discursive strategies where adding to does not add up but serves to disturb the calculation of power and knowledge, producing other spaces of subaltern signification. (Bhabha 1994, 162)

Qahera manages to disrupt the calculations of the condescending knowledge of the West and the gripping power of the East by occupying a middle positionality instead of siding with one of the extremes.

The first panel in Part Two is a wide, horizontal one that highlights a computer at the centre, forefront position, open at a page featuring "FEMEN protests at 
mosque" (Qahera 2013, Part 2). The dark, shadowed background reveals Qahera's weapon wall, with all sorts of swords, knives, whips, axes, archery bag, and ropes, along with two of her long attires hanging neatly and visibly. Mohamed's positioning of Qahera's costume, her hijab, signals that she "wears the hijab not to conceal her identity (as many superheroes do) but to project her identity. Indeed, her power seems to come from her traditional dress, as she is empowered by her choice to wear the hijab despite critiques of the possibilities of Islamic feminisms" (Ivey 2015, 384). The following panels reveal FEMEN protesters, with their distinguishing flower tiaras and bare breasts (which Mohamed covers with black batches), shouting "FEMEN Akbar" to signify that their god is a woman. Mohamed's choice to cover the ladies' naked tops signals the "de-emphasizing [of] FEMEN's visual political weapon (their nudity) while emphasizing the strength of her own traditional garment (her hijab)" (Ivey 2015, 386). Qahera's costume - embraced by choice - becomes a visible objection to FEMEN's appearance/ideology.

Upon viewing Qahera, FEMEN protesters rush to this Muslim woman who clearly needs saving, because "Oh look! You can see it in her eyes!! 'Help me!'” - a cry to which Mohamed draws fire instead of the pupils in the eyes of her superhero in a single, focused, close-up-on-the eyes panel. Mohamed's response to such "rescue" attempts are easily interpreted along what Homi Bhabha describes as the "reversal of the process of domination ... that turns the gaze of the discriminated back upon the eye of power" $(1994,112)$. They urge her to "take off [her] oppression and join [them]", an invitation to which Qahera responds by raising her sword and grouping them together in a bundle that she flies away with and leaves dangling from a tree branch, on a cliff. The scene is reminiscent of the punishment she inflicted upon the Muslim fanatic, but while in both cases the extremist is punished by being hung somewhere, the method differs with each case. The Muslim Sheikh is hanging from a laundry rope, closely related to Arab women's housework and culture, while FEMEN women are deposited away from the community in a deserted valley.

Christina L. Ivey accuses FEMEN - and similarly radical groups - of practicing "epistemic violence" against Muslim feminists, by operating under an aggressive view of agency and disregarding their own privileged positions which makes them unable to communicate with women lacking such privileges or descending from different cultures: "FEMEN's focus on physical depictions of Muslim women feeds into the colonialist mentality that inevitably affects the ways Muslim women are perceived. ... Possibilities for solidarity among feminist causes are destroyed due to a lack of understanding of cultural contexts" $(2015,385-86)$. It is particularly this gap between the perceived and the actual 
that creates the difficulty of understanding. Western feminists are mostly unable to see Muslim women as anything other than "rescue material" and fail to see the possibility of their change on their own terms (Figure 4). It is thus Mohamed's message through the webcomic that the "notion of the Muslim Woman as synonymous with passivity must be challenged continually by notions of muslim [sic] women as active agents in the third space" (Khan 1998, 490). Qahera is thus an example of Muslim, Arab, post-colonial women seeking agency and creating opportunities for it.
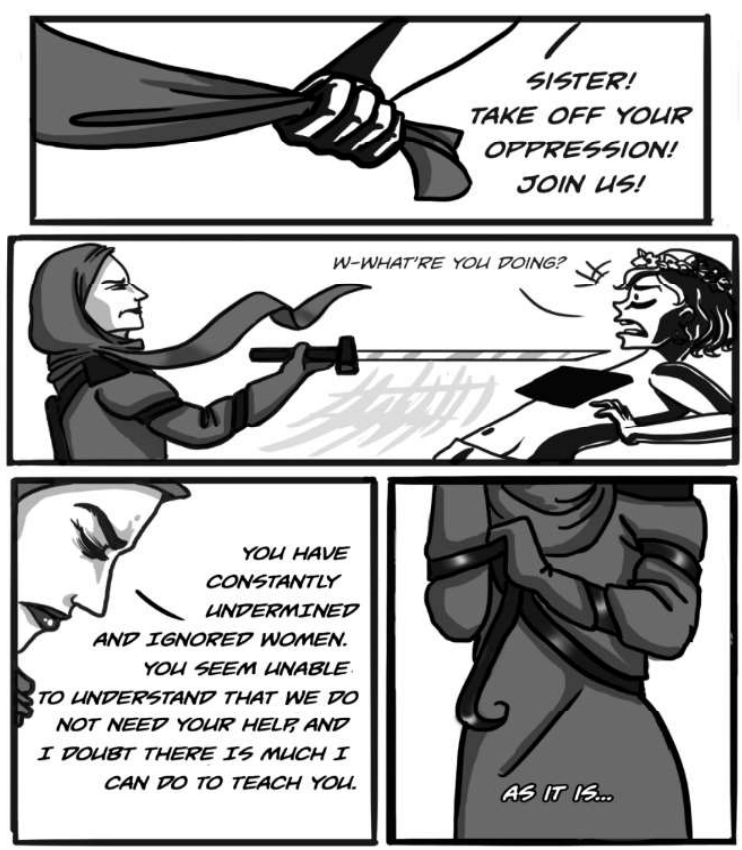

Figure 4, Qahera 2013, Part 2

The same line of criticizing the huge polarity between Islamic and Western views regarding women is highlighted, two years later, in Part Seven of the webcomic. Posted on July 28, 2015, the part features the arguments with and against hijab. The importance of this part stems from the fact that the secular/Islamic binary, with its projection of the secular as modern and preservative of women's rights, versus the Islamic as primitive and suppressive of them, highlights the veil as a main sign of either women's freedom or submissiveness (E1 Said, Meari, and Pratt 2015, 20-21). Qahera denounces both the Western condescending view that seeks to "liberate and rescue" women from their suffocating attire (Figure 5), and the Islamic view that compares women to wrapped candy, treasured gems, dear money, and chickens, that are too precious 
to be exposed to the outside world (Figure 6) and must be covered (Qahera 2015, Part 7). Unlike both Arab feminists who challenge misogyny by defying all Arab and Muslim practices and Western webcomics that "challenge misogyny as form by producing a range of liberated women's bodies on the page" (Galvan 2015, 204), Mohamed creates a third space which "serves as a rebuttal or corrective to regulating rigid views and suggests that identity is a complex, ambivalent, negotiable, and somewhat contested space where polarities do not apply" (English 2005, 87). Qahera defies all Western attempts at Westernizing or victimizing her; instead, she embraces the Arab/Muslim heritage on her own terms, seeks agency, negotiates, and constructs her unique identity.
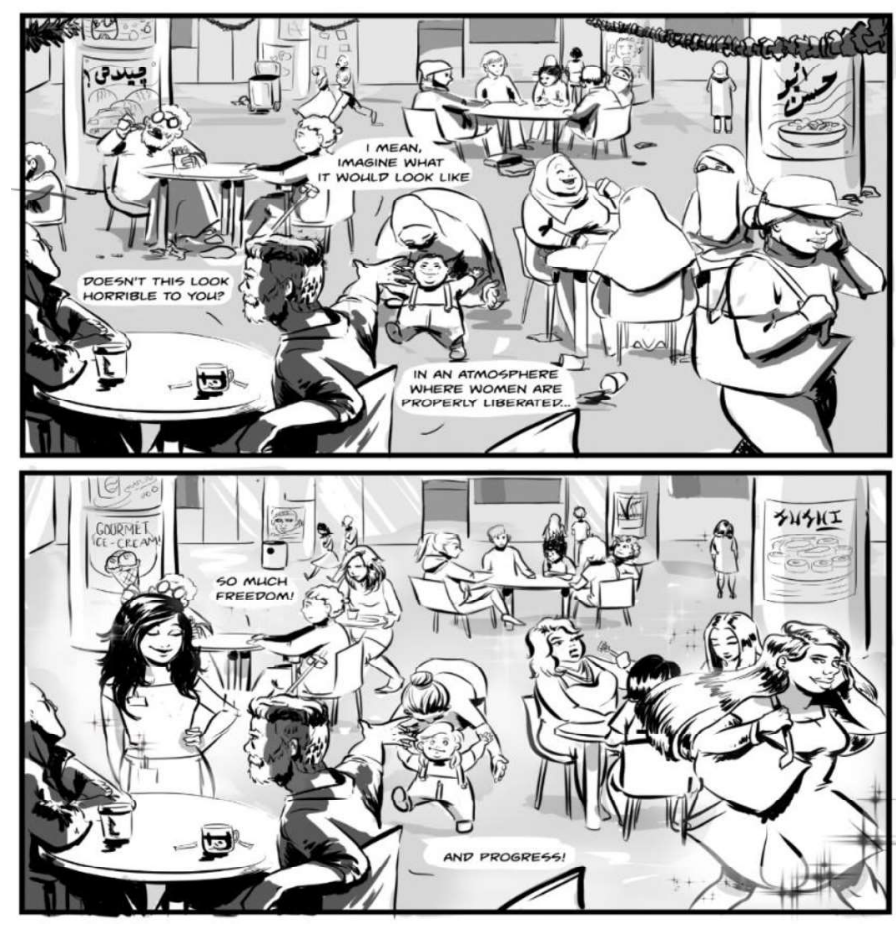

Figure 5, Qahera 2015, Part 7.

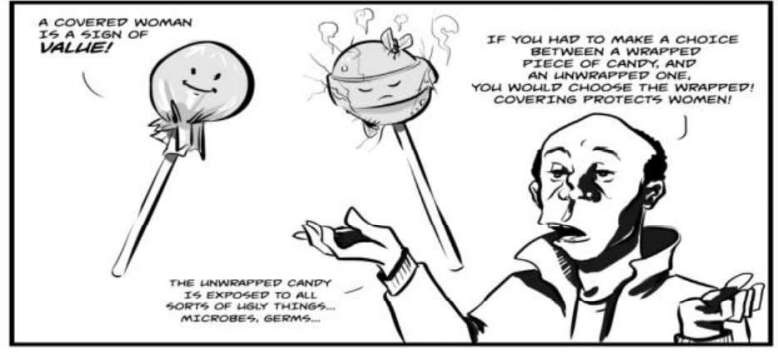

Figure 6, Qahera 2015, Part 7. 


\section{Individual/Collective Dichotomy}

This section discusses four parts that tackle the negotiation/construction of the female identity within the dichotomy of the individual/collective. Parts Three and Four deal with the sexual harassment women are constantly exposed to in the streets; the former addresses an individual case, while the later exposes the collective suffering of women against the backdrop of the revolution. Parts Six and Eight deal with the level of accountability an individual should have and discuss this from an Arab nationalistic stance in the former, and a local individual one in the latter.

Qahera's third comic focuses on individual sexual harassment. The way the characters are drawn in each panel delineates a dramatic scene and clarifies their purpose in the plot/comic as per Mohamed's design. In the first panel, a girl (Layla) is walking in the street and only her legs from the knee down can be seen, wearing trousers, and followed closely by a male foot. Behind her, three women are visible, two of whom are also being followed by men. This opening panel sets the scene and alludes to the prevalence of sexual harassment by giving the readers a glimpse of it before having the time to identify Layla as a distinct character rather than a generic Egyptian girl. In fact, Mohamed states, in her comment on the comic, that "the majority of the themes in this comic are based on real experiences with street harassment" (Qahera 2013, Part 3). The harasser grabs Layla from behind, at which she shouts at the top of her lungs, with extreme anger drawn clearly in the look of her eyes, and points him out to the passers-by in order to "Stop him" (Figure 7). Layla's accusatory pointing finger is magnified, and her hair can be seen edging out of the panel and into the gutter. So, "more than just an absence of visual image, the gutter serves as a site of differentiation. It is less a site in which the reader imagines events and dialogue that might occur between the panels than a topological gulf ... Indeed, there is literally no story to represent within that space but only connections to be made" (Dittmer and Latham 2015, 436). Layla's body language escapes the limits of the panel, is contorted, reeking with power and action in order to give the impression that this character refuses to be contained or cornered.

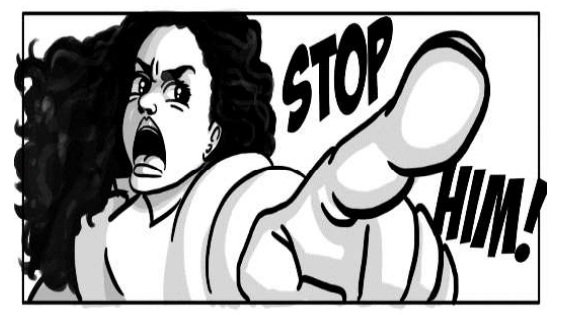

Figure 7, Qahera 2013, Part 3. 
Layla's confidence is shattered as the system fails her through the police officer who tells her that she is to blame for not being dressed modestly and no one will sympathize with her, summarizing society's patriarchal view that she can press charges if she likes, but "Everyone will just end up blaming [her] for ruining that poor guy's future" (Qahera 2013, Part 3). The change in Layla's character is not verbally voiced, but rather visibly delineated through her facial expressions, stance and posture, which change significantly as she steps out of the police station, and into the second harassment of the day. The look of confidence and straight shoulders that she started the comic with disappear, giving room to a broken look, folded hands, and a bent head (Figure 8).

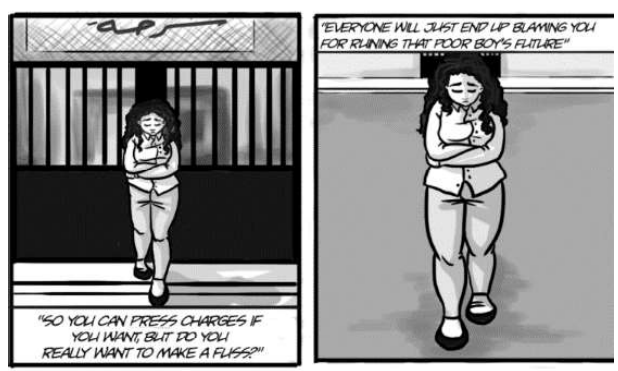

Figure 8, Qahera 2013, Part 3.

After she gets violently harassed for the second time, she is drawn curling in on herself without any borders in the panel and without her attackers in the picture to focus on her own broken spirit after being forced to surrender at knifepoint (Figure 9). The panel is mirrored against three small ones showcasing Layla's entrapment between two sets of attackers, where one of the attackers' fingertips cross his panel and intrude on Layla's, clearly signifying the violation of her personal space. Qahera's intervention here tips the scale in Layla's favour, restoring her confidence and incapacitating her attackers. It is worth noting that while Layla's and Qahera's faces are clear and white, the attackers' faces are heavily shadowed, showing both Egyptian women's fear and Mohamed's disdain for these predators. Qahera's interference creates the third space Layla needed in order to move on. Instead of yielding to the corrupt patriarchal system or being an outcast for opposing it, she now has an ideal to look up to, a feeling that she will not be defeated whenever she voices her opinion.

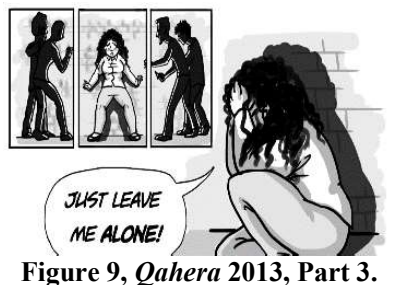


The final panel of this comic - in which Qahera leaves the attackers hung up on the walls of the police station with the words "These men are perverts written below their feet in both English and Arabic - is particularly interesting. Qahera embarrasses the authorities by publicly doing their job for them and declaring them wrong for not pressing charges against the harassers; "questioning the authority of the state may be imprudent, but it is also a praiseworthy exercise of moral autonomy" (Pratt 2009, 108). Qahera's message is a scandalous public spectacle, yet there are no spectators. Unlike the previous comic, which ends with Qahera personally schooling the activists of "FEMEN," this comic ends in a highly theatrical panel in which even Qahera herself does not appear, delivering a message not to Qahera's fictional community, but to Qahera's virtual community, and creating a third space where the "eye of the reader moves back and forth, up and down, adding new images to those already seen and then revisiting old images to produce a narrative from the montage" (Dittmer and Latham 2015, 435). The montaged narrative is one that forces readers to realise their own involvement, to simply see it not as a detached webcomic, but as a projection of real societal issues.

Qahera's fourth comic moves from the individual to the collective, from the personal to the public, also through harassment. It differs from other parts in that it does not follow a linear sequence of events, but describes the increased harassment inflicted upon women during demonstrations. In her commentary on this comic, Mohamed states that it was intended more as a tribute to Egyptian women than a webcomic (Qahera 2013, Part 4). It begins with Qahera standing on top, overlooking Tahrir square, with its immense crowds during the revolution time. She states that she does her best to protect women from harassment there, which is not easy in a crowd. A panel features arranged harassment for a price, and another delineates the actual attacks on women as a means to silence them and get them to retreat to the alleged safety of their homes. Shereen Abouelnaga describes this in terms of the "post-revolution sociocultural clash, where women's bodies turned into a battlefield" $(2015,41)$, and where their insistence on securing their space of appearance in Tahrir square was met by louder neo-conservative voices that "fiercely determined to keep women's agency mediated through the male designation" $(2015,42){ }^{7}$ Both Mohamed and Qahera reject the calls for women's sequestration under pretexts of protection. Mohamed's proposed suggestion is a third space that saves women from both harassment and isolation by creating a safe environment where they could function as active members of the society.

Qahera declares that she does her best, but sometimes she is too late, and sometimes she is not needed. This can be clearly observed in two side by side panels where Mohamed replicates images of landmark Egyptian 
incidents/controversies that are nevertheless likely to be familiar to the targeted Western audience. The first panel where a woman is being stripped and beaten is reminiscent of the Niqabi woman who suffered this in a 2011 protest, in an incident dubbed by foreign media as "Blue Bra Girl." (almost a replica of the photo published by Western media), Mohamed recalls not only the incident itself, but its massive fallout in one panel. Another simple addition that delivers Mohamed's message regarding the dangers of harassers was drawing a frame around each of the faces of the harassers, which transforms their presence in the panel into a collection of mugshots (Figure 10), foreshadowing her later statement that their harassment of women "is a crime" (Qahera 2013, Part 4). Next to it is a panel featuring Egyptian men holding hands to form a ring around the women in the protest to protect them from harassment and/or violence in the crowd. By posting means of societal solidarity via cyberspace, Mohamed is "engaged in conscientization in third spaces and learning to voice dissent, dialogue, create democratic structures, and monitor those structures to ascertain transparency and citizen participation" (Boumlik and Schwartz 2016, 326). Her panels advocate social responsibility and urge men to condemn violent behaviour rather than blame the victim or find solution in hiding women in the alleged safety of home.

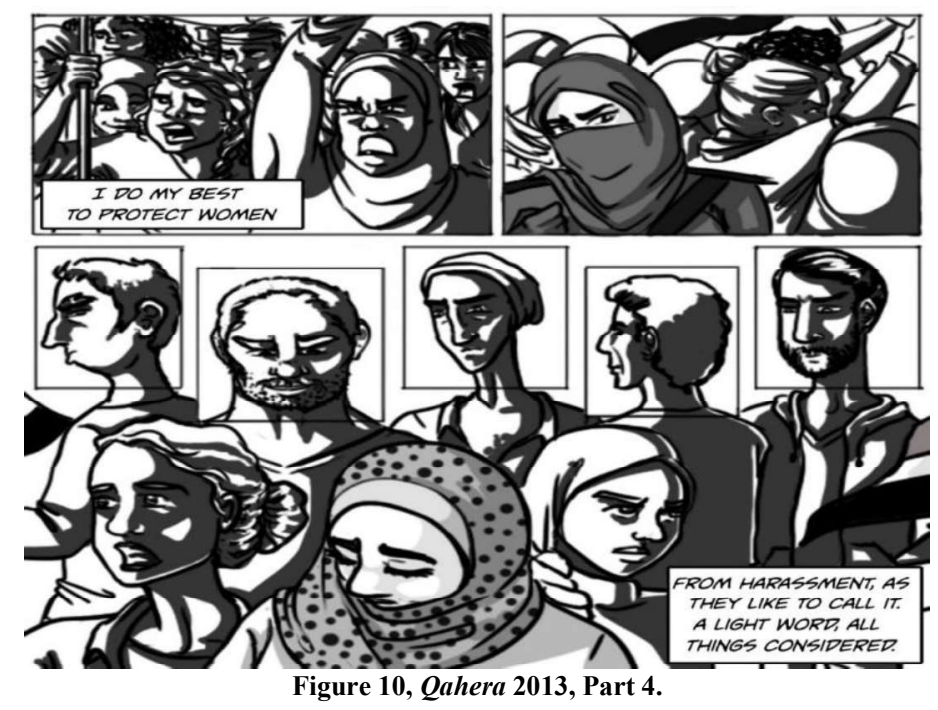

The dichotomy between black and white is also highlighted very distinctly towards the end of the comic as Qahera, first towering over the crowds, jumps down amid the protestors and starts looking for offenders. In this panel, the crowd is seen as one large black dot while Qahera is drawn entirely in white. 
The decision to draw her as a white silhouette rather than her customary black figure with a white outline reinforces the image of Qahera as an outnumbered righteous presence in the middle of a threatening atmosphere (Figure 11). Qahera begins the comic with the statement "I AM A SUPERHERO BECAUSE I HAVE SUPERPOWERS" and ends it with a tribute: "I AM A SUPERHERO BECAUSE I HAVE SUPERPOWERS. THEY ARE SUPERHEROS BECAUSE THEY DO NOT" (Qahera 2013, Part 4). Put this way, Mohamed transforms ordinary Egyptian women to superheroes for their ability to deal with the hardships of everyday life. The drawing of the female characters in the final panel indicates both variety and inclusion. The presence of hijabi, niqabi and unveiled women at the forefront of the panel indicates that Mohamed attempts to speak for all women within the Egyptian society. Qahera's appeal stems from both its unique approach and the fact that it "frames itself as a positive intervention, rather than a negative defence" (Jones 2017, 1089). Introducing herself as a doer, Qahera becomes the subject in her own world, an occupier of the centre rather than a footnote in the margin. Qahera's final caption implies that each one thus enjoys the same gendered subjectivity that enabled Qahera to find her own third space and escape both the confinement of an oppressive patriarchal environment and the estrangement of a Western feminist framework.

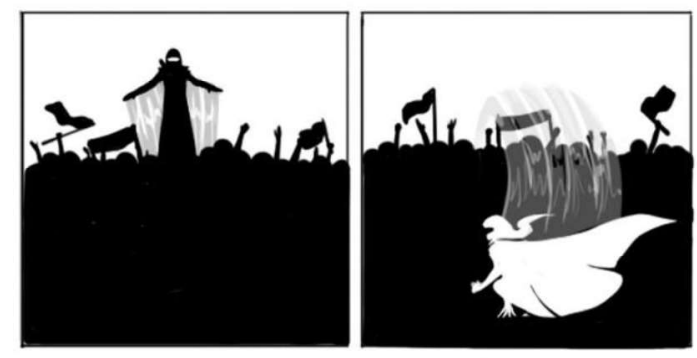

Figure 11, Qahera 2013, Part 4.

On 29 July 2014, Mohamed posted her sixth comic, which is about Gaza and the Palestinian martyrs, the message being that the individual contributes to the collective responsibility. She describes this comic as "a quick comic on accountability. Sometimes it is important to disassociate yourself from patriotism and realise when you are contributing to the suffering of others" (Qahera 2014, Part 6), thus announcing that her interests go beyond the microcosmic political matters to encompass humanitarian ones. Mohamed resorts to the same technique she used in the comic on harassment, namely showing a huge list of the names of "Gazan martyrs" hanging on a building overlooking a wide street with no protestors, security guards, or even the average passers-by to observe it. This is another example of Mohamed cutting out the 
middle man (Qahera) and conversing directly with her readers in an attempt to motivate a pro-Palestinian sentiment and shame Arab communities for their perceived passivity and selfishness (Figure 12). The panel here does not employ a caption but has the words "Their blood is on our hands too," painted all over the street so as to present them, not as Qahera's subjective opinion given a narrative voice, but as a statement of fact and a firm condemnation. ${ }^{9}$

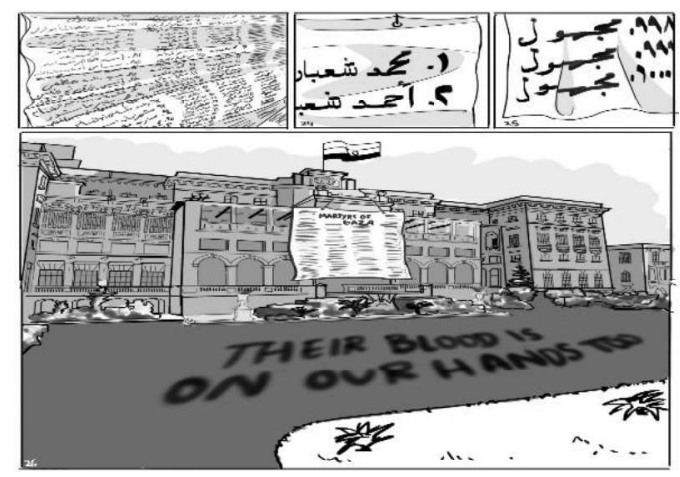

Figure 12, Qahera 2014, Part 6.

Mohamed's final comic, dated 25 August 2015, is a pessimistic delineation of the frustrated individual against a suffocating collective. Qahera asks "what does it mean to be a superhero? what does it mean to fly?" (Qahera 2015, Part 8 ). The comic traces the envy some women would feel towards Qahera since they cannot enjoy her powers. The sadness with which a woman tells Qahera that her brother could have benefitted much more from her powers is another example of "gendered subjectivity." Reminded of her privileges, Qahera takes another look at the sky from below, noticing the crowd, litter, street children, and all the agonies of the poor city which are forgotten in the big picture of super heroism (Figure 13).

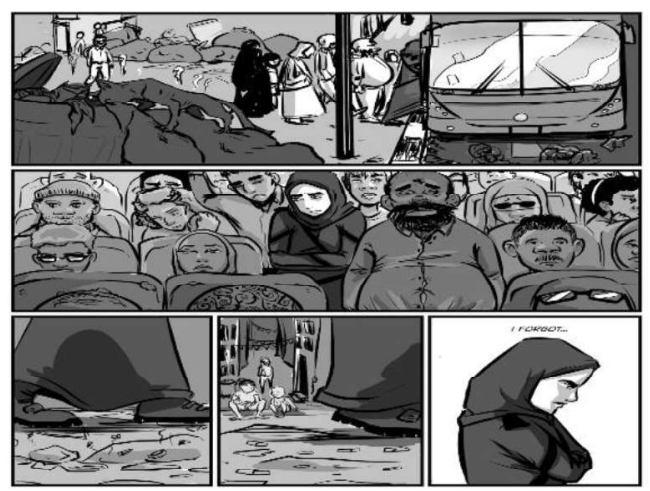

Figure 13, Qahera 2015, Part 8. 
The comic ends with Qahera buying two air tickets for the sad woman and her brother; she stands watching their flight as it passes by her. Mohamed comments on the comic saying that "this comic may be a little difficult to understand for those of you in countries people immigrate to not from" (Qahera 2015, Part 8). That the final comic ends with two get-away tickets is a sad result after all! They are a reminder that third spaces are not always successful, that some women would remain trapped in their suffocating world, that even superheroes might not win, and that life just does not get any better for some people.

\section{Concluding Remarks}

Though the number and size of webcomics posted by Deena Mohamed is not big, it is still effective and manages to stir still waters. Mohamed's use of shapes and delineation of her protagonist's body in the comics is unique, in the sense that "[t]he Juxtaposition of text and image in these comics allows them to more viscerally realize and challenge the tenets of feminism through women's own bodies. How might we value visual documents in a genealogy of feminism - not just as artifacts - but as instigators and shapers of rhetoric and ideas?" (Galvan $2015,205)$. While Galvan's question in the previous quote is directed to a different feminist arena, it is just as valid with Deena Mohamed. The totally covered body of her superhero stands against the naked images of Western comics, as Qahera "proves its underlying message of independence from both misogyny and the co-optation of women's movements resonates with readers. Qahera embodies Egyptian women's ability to cultivate their own meaning of 'feminism,' and their own power to defeat sexism and the problems that come with it" (Chang 2013). Qahera/Qahera become the third space that attempts to maintain middle ground amid extremes.

Deena Mohamed is an artist with a unique style. Each part within her eightpart webcomic enjoys the dramatic elements that make it appeal to the readers; namely, a plot, a main character (Qahera), secondary characters, a setting, and an engaging narrative. Mohamed employs the black and white binary throughout all the panels, producing shades of the inevitable grey, where many women actually reside. She uses similar sized and shaped frames to indicate similarities between apparently different entities, and resorts to subtle intricacies in the drawing to deliver her message, such as enlarging a victim's accusatory finger when pointing at a perpetrator or drawing frames around harassers' faces to make them resemble mugshots or allowing criminals' fingers to escape their frame and infiltrate the frame of the victim's panel. Mohamed uses Qahera to voice her opinions, yet sometimes she dispenses with her and presents a characterless panel with a message addressed directly, not to the fictional 
characters within the comic, but to the virtual readers of the comic. Mohamed's style pushes the readers to realise their own involvement and engage in a third space of their own.

Qahera is a webcomic that challenges the conventions of identity construction dictated by state, patriarchy, religious institutions, and sociocultural orientations. Within a broad interpretation of Homi Bhaba's Third Space theory, Qahera becomes a site for the negotiation of identity construction and re-construction by mapping the webcomic's virtual world onto our own and creating a new space/perspective/identity. Qahera's character poses a challenge on several levels. First, as a webcomic character, Qahera's Islamic attire and independent existence challenge the naked figures of Western female superheroes, who appear as spin-offs from their male counterparts, thus creating a uniquely Egyptian, female, Muslim superhero. Second, Deena Mohamed/Qahera's firm rejection to abide by either the secular or the extreme Islamic interpretations of what a woman should be like helps create a third space where women could enjoy gendered subjectivity and construct an identity that is uniquely unimpeded by Western stereotypes or Eastern clichés. Third, on the level of the individual versus the collective, Mohamed proposes a third space wherein women are neither sequestered within isolated spaces under pretexts of protection, nor violated for attempting to contribute to the public sphere. Through Qahera, Deena Mohamed advocates a third space where women would enjoy the accountability that accompanies an act of agency.

\section{Endnotes}

\footnotetext{
${ }^{1}$ For a full survey of the historiography of comics see the introduction of Comics and Power: Representing and Questioning Culture, Subjects and Communities, edited by Cortsen, Rikke Platz, Erin La Cour, and Anne Magnussen, 2015.

${ }^{2}$ Shortly after its launch, Qahera went viral, attracting the attention of about 500,000 visitors, and gaining interest from international media outlets such as The Daily Beast, BBC, Foreign Policy, and The Times. It won the Cairo Comix Festival award for best digital comics series in 2015.

${ }^{3}$ Mohamed opts for a light comic in Part Five, indicating that "this comic is intended for amusement and should only be taken perhaps 12\% seriously" (Qahera 2013, Part 5). Qahera appears with Layla, the girl she rescued from harassers in Part Three, with the latter making fun of her name and cracking puns at the Qahera/Cairo choice of her parents. The Arabic version is much more revealing in this comic as it relates to the Egyptian culture in a way that is almost untranslatable! Perhaps this is the reason why Mohamed wrote this particular comic in Arabic first and then translated it into English,
} 
describing the difficulty of the process: "Translating this stretch into English was more difficult than translating all the previous comics put together into Arabic" (Mohamed 2016, 144). Layla forces her to listen to a misogynistic Arabic song called "I am Si Al Sayed," referring to the famous chauvinistic character from Naguib Mahfouz's trilogy, featuring the all-controlling male whose words cannot be disputed. Qahera fantasizes about beating up the singer and throwing him away after making him confess he is not Si Al Sayed, but just "sees," as this "punchline is a colloquial Egyptian insult. Si Al Sayed is usually pronounced as SiSayed in Egyptian dialect; it is shortened further in the comic to read sees - a term usually used to refer to effeminate and feeble men" (Mohamed 2016, p. 144). Qahera's fantasy comically avenges all women by humiliating the most macho figure in Arabic literature.

${ }^{4}$ It is worth noting though that the intricacies of translation are beyond the focus of the present paper, which is mainly concerned with the effect of such a linguistic shift on the identity formation of both superhero and recipients.

${ }^{5}$ It is significant that Mohamed chooses a hijabi superhero to address the West, while Marvel (a leading American entertainment company in the fields of comics and movies) announces that it is launching its first movie with a Muslim, female superhero, Ms. Marvel, whose alter ego in the comic books is the Muslim Kamala Khan, a PakistaniAmerican teenager from New Jersey, who is - ironically - unveiled.

${ }^{6}$ All panels from Qahera are reprinted with permission from author.

${ }^{7}$ For a full discussion of women's endeavors to reconstruct their identity during and after the revolution, see Shereen Abouelnaga's Women in Revolutionary Egypt: Gender and the New Geographics of Identity, 2016.

${ }^{8}$ The incident was widely discussed and reported by almost all international media outlets.

${ }^{9}$ It is noteworthy that Mohamed published the list of martyrs in the comic and updated the full list to be available on the site too, indicating that at the time of writing the comic the number was 1000 , but the full list is updated and posted constantly.

\section{Works Cited}

Abouelnaga, Shereen. 2016. Women in Revolutionary Egypt: Gender and the New Geographics of Identity. Cairo: The American University in Cairo Press. -----. 2015. "Reconstructing Gender in Post-Revolution Egypt." In Rethinking Gender in Revolutions and Resistance: Lessons from the Arab World, edited by Maha El Said, Lena Meari and Nicola Pratt. London: Zed Books Ltd, 3558.

Barkuzar, Dubbati. 2017. "The Woman in Hijab as a Freak: Super(Muslim)woman in Deena Mohamed's Webcomic Qahera", Journal of Graphic Novels and Comics 8, no. 5: 433-449. 
Bhabha, Homi K. 1994. The Location of Culture. London: Routledge.

Boumlik, Habiba, and Joni Schwartz. 2016. "Conscientization and Third Space: A Case Study of Tunisian Activism." Adult Education Quarterly 66, no. 4: 319-335. Academic Search Complete, EBSCOhost (accessed Jan. 20, 2018).

Chang, Chalaine. 2013. "Qahera: Striking a Blow for Egyptian Women's Autonomy." Bitch Magazine: Feminist Response to Pop Culture 61, no.6. Academic Search Complete, EBSCOhost (accessed June 26, 2017).

Coogan, Peter. 2009. "The Definition of the Superhero." In A Comics Studies Reader, edited by Jeet Heer and Kent Worcester. Jackson: University Press of Mississippi, 77-93.

Cooke, Miriam. 2000. "Multiple Critique: Islamic Feminist Rhetorical Strategies."Nepantla: Views from South 1, no.1: 91-110. Academic Search Complete, EBSCOhost (accessed 1 June 2017).

Cortsen, Rikke Platz, Erin La Cour, and Anne Magnussen, Eds. 2015. Comics and Power: Representing and Questioning Culture, Subjects and Communities. UK: Cambridge Scholars Publishing.

Dittmer, Jason, and Alan Latham. 2015. "The Rut and the Gutter: Space and Time in Graphic Narrative." Cultural Geographies 22, no. 3: 427-444.

El Said, M., Meari, L., \& Pratt, N. Eds. 2015. Rethinking Gender in Revolutions and Resistance: Lessons from the Arab World. London: Zed Books.

English, Leona M. 2005. "Third Space Practitioners: Women Educating for Justice in the Global South." Adult Education Quarterly 55, no. 2 (February): 85-100. Academic Search Complete, EBSCOhost (accessed 20 January 2018).

FEMEN. 2018. https://femen.org/about-us/

Galvan, Margaret. 2015. "Feminism Underground: The Comics Rhetoric of Lee Marrs and Roberta Gregory" Women's Studies Quarterly 43, no. 3/4, THE 1970s (FALL/WINTER): 203-222.

Ikas, Karin, and Gerhard Wagner, Eds. 2009. Communicating in the Third Space. NY: Routledge.

Ivey, Christina L. 2015. "Combating Epistemic Violence with Islamic Feminism: Qahera vs. FEMEN." Women's Studies in Communication no. 38: 384-387.

Jones, Bethan. 2017. "Producing and Branding Gender in Comics: My So-Called Secret Identity and the Ambivalence of an Alternative Address." Palabra Clave 20, no. 4 (December): 1073-1104.

Khan, Shahnaz. 1998. "Muslim Women: Negotiations in the Third Space." Signs 23, no. 2 (Winter): 463-494. 
Mohamed, Deena. 2016. "On Translating a Superhero: Language and Webcomics." In Translating Dissent: Voices from and with the Egyptian Revolution. Ed. Mona Baker. NY: Routledge, 137-147.

----. 2015. Qahera. "Part 8: On Flight." 25 August 2015. http://qaherathesuperhero.com/post/127596119696

-----. 2015. Qahera. "Part 7: On Women's Choices." 28 July 2015. http://qaherathesuperhero.com/post/125314061196

----. 2014. Qahera. "Part 6: On Accountability." 29 July 2014. http://qaherathesuperhero.com/post/93179167086

----. 2014. Qahera, "Part 5: On Music (Sort of)." 6 January 2014. http://qaherathesuperhero.com/post/72511540239

----. 2013. Qahera. "Part 4: On Protests." 25 November 2013. http://qaherathesuperhero.com/post/68110255239

-----. 2013. Qahera. "Part 3: On Sexual Harrassment." 2 September 2013. http://qaherathesuperhero.com/post/60081962515

----. 2013. Qahera. "Part 2 : On FEMEN. “ 20 July 2013. http://qaherathesuperhero.com/post/61173083361

----. 2013. Qahera. "Part 1 : Brainstorm." 30 June 2013. http://qaherathesuperhero.com/post/64031330049

Nagarajan, Chitra. 2013. "Femen's Obsession with Nudity Feeds a Racist Colonial Feminism." The Guardian. 11 April 2013. https://www.theguardian.com/commentisfree/2013/apr/11/femen-nudityracist-colonial-feminism

Packer, Randall. 2014. Third Space. 29 January 2014. http://www.randallpacker.com/third-space/

Pratt, Henry John. 2009. "Medium Specificity and the Ethics of Narrative in Comics." Storyworlds: A Journal of Narrative Studies 1: 97-113.

Scott, Suzanne. 2015. "The Hawkeye Initiative: Pinning Down Transformative Feminisms in Comic-Book Culture through Superhero Crossplay Fan Art." Cinema Journal 55, no. 1: 150-160. 